\title{
The Importance of Industrial Ecology in Engineering Education for
}

\section{Sustainable Development}

\author{
Wahidul K. Biswas \\ Centre of Excellence in Cleaner Production, Curtin University, Bentley, Western Australia 6845, Australia \\ E-mail: w.biswas@curtin.edu.au
}

Submitted 6 February 2011

Revised 3April 2011

\begin{abstract}
Purpose - The purpose of this paper is to show how industrial ecology can facilitate the achievement of sustainable development through its incorporation into an engineering curriculum.
\end{abstract}

Design, methodology and approach - A model for assessing sustainability learning outcomes due to the incorporation of the concept of industrial ecology into undergraduate and postgraduate engineering programs has been developed. This model assesses how the Engineering Faculty at Curtin University has included a core engineering unit (Engineering for Sustainable Development) and four postgraduate units (Cleaner Production Tools, Ecoefficiency, Industrial Ecology and Sustainable Technology) in its undergraduate and postgraduate engineering program to enable modern engineering education to reflect the benefits of industrial ecology in the implementation of sustainable engineering solutions and 
decision-making processes. Using this model, this paper demonstrates how the syllabus, interdisciplinary and multidisciplinary assignment tasks, lectures and tutorials have been developed since 2006 in order to develop the concept of industrial ecology in undergraduate and postgraduate engineering education. The paper has also analysed the different teaching methods that have been applied since 2006 to generate increased student satisfaction in these new and challenging subjects.

Findings - The university environment can temper the potential outcomes from increasing the sustainability content in engineering education given the general lack of student maturity in understanding the value of sustainability objectives together with course limitations on sustainability content and the arduous and lengthy processes involved in changing course curricula.

Research limitations and implications - Since the Engineering for Sustainable Development unit has been introduced only recently, it was beyond the scope of the research to interview graduate engineers who completed this unit to investigate how they have applied the concept of industrial ecology to achieve sustainability outcomes in their workplaces.

Originality and value - This research is distinct in that it investigated the implications of the incorporation of industrial ecology into the engineering curriculum.

Key words: Industrial Ecology, Sustainable Development, Engineering Education

Paper type Viewpoint 


\section{Introduction}

This paper presents the results of the introduction of the concept of industrial ecology in the engineering curriculum to enhance students' knowledge of engineering for sustainable development (ESD). Many professional engineers are developing projects to achieve sustainable solutions, but there is still a gap between the knowledge that they acquire in their university degree and the concepts of sustainability they practise as an engineer (Loden and Biswas, 2010). Economic, social, intergenerational and intragenerational aspects all need to be considered in engineering design to attain sustainable solutions.

The engineering context of sustainability involves the design and management of sustainable technology, research into environmental and social impacts and management of resources from cradle to cradle (Boyle, 2004). Industrial ecology takes all these aspects into account as it encompasses a broad range of sustainability related topics, including life cycle assessment, cleaner production and eco-efficiency strategies, industrial symbiosis, green chemistry, green engineering and design for the environment, that help conserve resources and mitigate pollution for current and future generations.

Technology revolutionises society and social issues are at stake with every innovation process and, therefore, an engineer should be trained not just as a pure designer of a technology, but as a social engineer (Mulder, 2004). According to a national review of engineering education, there are evolving demands for future engineers, including the ability to communicate more clearly, to function effectively in multidisciplinary and multicultural environments, and to understand their ethical, social, professional, business, economic, cultural, global and environmental responsibilities (Bryce et al., 2004) . However, sometimes the solutions developed by engineers are seen as creating new problems with technological solutions to environmental problems often recognised as inferior to social solutions. For 
example, DDT, which is used as a pesticide to kill mosquitoes, has caused tens of millions of needless deaths and hampered agricultural production. Love Canal pollution, the Three Mile Island accident, the Bhopal gas explosion, the Chernobyl explosion and the Mexican Gulf oil spill are some engineering catastrophes that have caused considerable social and environmental risks.

Development of new technologies can only take place if technologists and engineers have a good understanding of the needs of those who will be affected by the new technologies. Engineering innovations need to respond to social demand while taking ecological and economic principles into account.

University engineering degrees need to produce graduates who are able to apply sustainability principles throughout their professional career. Ultimately, over the next 20 years the majority of university engineering departments will make the transition to engineering education for sustainable development as society addresses the challenges of sustainable development, including climate change (Desha et al., 2009; Desha and Hargroves, 2009)

A small number of Australian universities - Curtin University, University of Technology, Sydney and The University of Sydney - offer Engineering for Sustainable Development for undergraduate students (Bryce et al., 2004; El-Zein et al., 2008). The Centre for Excellence in Cleaner Production (CECP) at Curtin University offers a unit on Engineering for Sustainable Development to all engineering departments in the Faculty of Engineering, where the concept of industrial ecology is taught to all engineering students to enable them to develop sustainable engineering solutions. The theory and case studies in this unit were based on CECP's 11 years experience in the area of industrial synergies, eco-efficiency and cleaner production for the Kwinana Industrial Council. 
This paper reviews the concept of industrial ecology in the engineering curriculum and its value in promoting sustainable engineering education. The paper discusses:

1. how industrial ecology has been included in the engineering curriculum at Curtin University

2. how industrial ecology relates to sustainable engineering

3. the learning outcomes of industrial ecology in the engineering curriculum

4. how education through the proper pedagogical strategies can make sustainable engineering learning achievable

5. how students have benefited from the concept of industrial ecology in their engineering education.

\section{Methodology}

In order to address the questions raised in the introduction, a theoretical framework for assessing sustainability learning outcomes due to incorporation of the concept of industrial ecology into undergraduate and postgraduate engineering programs has been developed.

The assessment framework has been built upon the concept of sustainability, industrial ecology and expected learning outcomes to assess how the Engineering Faculty at Curtin University has included a core engineering unit (Engineering for Sustainable Development) and four postgraduate units (Cleaner Production Tools, Eco-efficiency, Industrial Ecology and Sustainable Technology) in its undergraduate and postgraduate engineering program to enable modern engineering education to reflect the benefits of industrial ecology in the implementation of sustainable engineering solutions and decision-making processes.

Using this framework, the author investigated how the syllabus, interdisciplinary and multidisciplinary assignment tasks, lectures and tutorials have been developed since 2006 in 
order to develop the concept of industrial ecology in undergraduate and postgraduate engineering education. The evaluation reports of these industrial ecology units, published by the Teaching and Learning Department of Curtin University at the end of the semester, have been reviewed to obtain both qualitative and quantitative information.

This framework investigated the application of pedagogical strategies at the following two general levels that have been applied since 2006 to generate increased student satisfaction in these new and challenging subjects:

- passive learning: lecturing, writing exercises, problem demonstrations

- active learning: problem based learning (PBL), case studies.

Segalas et al. (2009) followed a similar approach in introducing sustainable development in engineering education.

Finally, feedback from former students who are now in the workforce has been collected to determine the implications of industrial ecology knowledge in attaining sustainable solutions in their professional carreer.

\section{Industrial ecology in the engineering curriculum}

\subsection{What does industrial ecology involve?}

Industrial ecology includes the following areas.

Life cycle assessment is a technique for assessing the environmental performance of a product, process or activity from cradle to cradle. Life cycle assessment helps identify the 'hotspots' or the stage or process requiring pollution mitigation strategies. Industrial symbiosis, cleaner production strategies, eco-efficiency strategies, green chemistry and 
biomimicry are some tools of industrial ecology which can be applied to hotspots to attain sustainable engineering solutions (Biswas, 2009; Biswas et al., 2010, Biswas et al., 2011).

Industrial symbiosis (industrial synergy) engages traditionally separate industries in a collective approach involving physical exchange of often surplus or waste materials, energy, water and/or by-products. The keys to industrial symbiosis are collaboration and synergistic possibilities offered by geographic proximity (Chertow, 2006). Some practical applications of industrial ecology are inspired by Kalundborg in Kwinana Industrial Area, Denmark, Western Australia, and there are many more examples on all continents. In Kalundborg in Denmark and Rotterdam in The Netherlands a range of by-product and utility sharing synergies was developed over a number of years (Ehrenfeld and Chertow 2002; Jacobsen 2006). Kwinana in Western Australia, which is Australia's largest mineral processing region, has been positioned as a leading international example of regional synergy implementation by successfully implementing 50 existing regional synergies (van Berkel, 2006; van Beers et al., 2008). For example, 70,000 tonnes of $\mathrm{CO}_{2}$ produced by the local fertiliser company at its ammonia plant in Kwinana is sold annually to a nearby alumina processing plant, thereby mitigating some of the emissions associated with fertiliser production (van Beers and Biswas, 2008).

Cleaner production aims to make more efficient use of natural resources and reduce the generation of wastes and emissions at the source. This is generally achieved through the implementation of any of five generic prevention practices: product modification, input substitution, technology modification, good housekeeping, and (on-site) recycling and reuse (Howgrave-Graham and van Berkel, 2007). This may be achieved through the delivery of competitively priced goods and services that satisfy human needs and bring quality of life, while progressively reducing ecological impacts and resource intensity throughout the life cycle to a level at least in line with the Earth's estimated carrying capacity. Eco-efficiency 
and cleaner production are complementary concepts, with eco-efficienty focusing on the strategic side of business ('value creation') and cleaner production on the operational side of business ('production') (van Berkel, 2007).

An eco-industrial park includes resource exchange networks where there is cleaner production at each facility, involves resource recovery and reuse, enhanced through industrial clustering, supportive infrastructure and eco-services providers (van Beers et al., 2007). The park design and management integrates into natural ecosystems, green facilities design and an environmental management system.

Green chemistry is the design, development and implementation of chemical products or processes to reduce or eliminate the use and generation of hazardous and toxic substances (Baird and Cann, 2006). It is aimed at reducing the dispersion and accumulation of synthetic chemical products in the environment. It is also aimed at less hazardous materials, processes and products.

Biomimicry describes how people learn from nature to generate sustainable solutions and designs. For example, a group led by Professor Rolf Muller at the University of Southern Denmark has studied bats' ears to develop new ultrasonic antennas for robots (Müller and Kuc, 2006).

All these concepts of industrial ecology help to conserve resources and enhance environmental improvement for present and future generations. According to Diesendorf (2000), sustainable development comprises various types of economic and social development that protect and restore the natural environment and social equity. For example, Biswas et al. (2001) developed an economically sustainable model to allow poor rural people to operate environmentally friendly and technologically appropriate businesses. This model enables the poorest people to obtain capital intensive renewable energy technology without outlaying any capital and provides competitive energy prices and wage rates to alleviate 
poverty.

\subsection{Undergraduate level}

Industrial ecology has been included in the Engineering for Sustainable Development unit which is offered to all undergraduate engineering students at Curtin University. The unit deals with the contribution of engineering to the development and implementation of sustainable solutions.

The content of the Engineering for Sustainable Development unit is broadly organised into three clusters:

Cluster 1: Sustainable Development is an introduction to the sustainable development agenda and debate, covering key sustainability issues (local, national and global) and key government, corporate response strategies and indigenous values and culture.

Cluster 2: Resource Management Tools and Practices outlines the basics of efficient resource utilisation in industrial scenarios, such as life cycle assessment, industrial symbiosis, cleaner production and eco-efficiency techniques.

Cluster 3: Sustainable Technology is an exploration of the role of technology (engineering) in achieving sustainable development, covering both sustainabilitydriven innovations as well as sustainability applications of emerging technologies.

The three learning outcomes for the Engineering for Sustainable Development unit that are related to industrial ecology are to:

1. achieve a sound understanding of the basic theories of cleaner production and the triple bottom line principles of sustainable development

2. acquire the ability to use key methods and tools for corporate environmental and sustainability engineering and management from a social, economic and environmental perspective 
3. strengthen multidisciplinary teamwork skills through group project participation and project delivery.

The concept of industrial ecology has been included in the first, second and third clusters of this unit and Figure 1 shows how the concept of industrial ecology can help attain learning outcomes to develop sustainable engineering solutions. Cluster 1 has been designed to enable students to understand the concept of sustainable development and sustainability and how engineering design affects economic, environmental and social aspects of sustainable development. Similar to Kamp (2006), the following two definitions of triple bottom line and impact on the environment due to population, affluence and technology (IPAT) [1] are used as guidelines for introducing the concept of industrial ecology and to design relevant and useful tools, methods and technologies for Clusters 2 and 3.

\section{$\begin{array}{lll}\text { Clusters } \quad \text { IE contents GOs } & \text { Goal }\end{array}$}

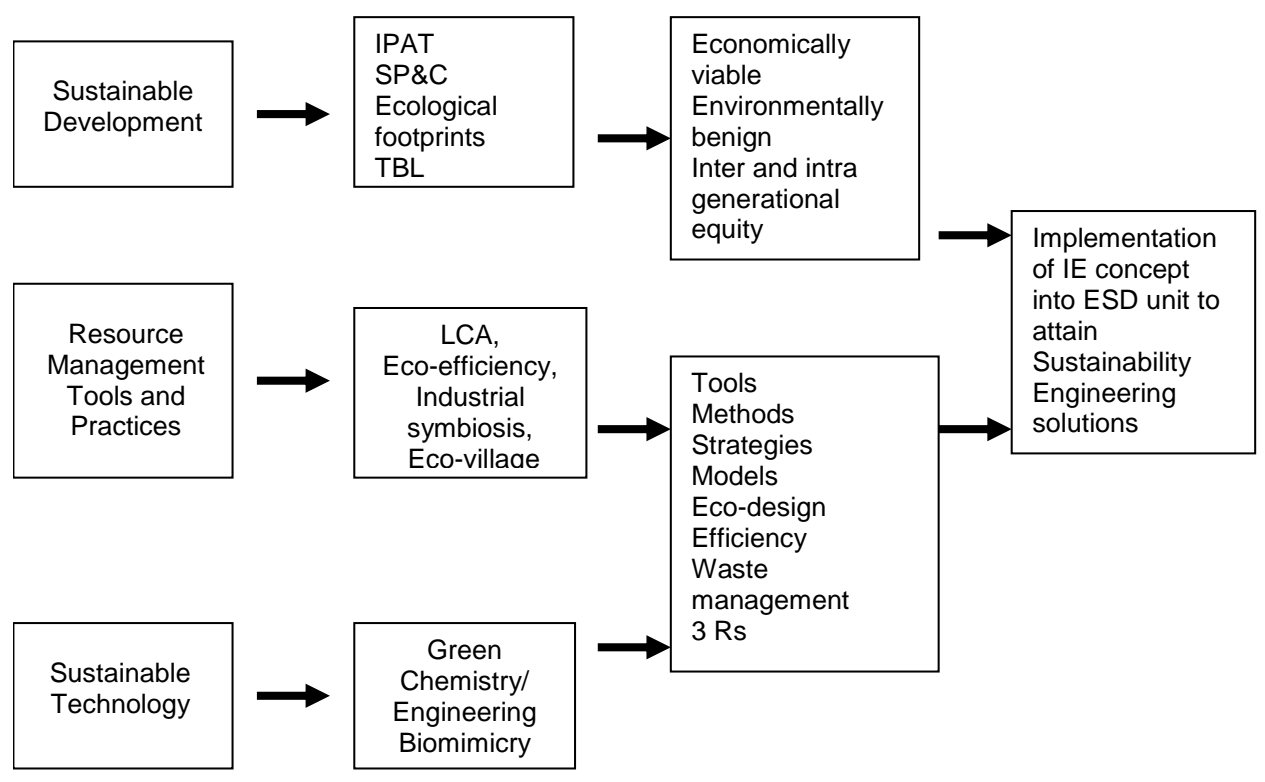

Figure 1. Model for incorporating industrial ecology into the engineering curriculum. 
When a technically feasible technology needs to be assessed from an economic, environmental and social perspective it is known as triple bottom line. Alternatively, a sustainable engineering design needs a balance between the pressure on the environment, social justice and economic growth.

In Cluster 2, students are introduced to life cycle assessment concepts and tools to assess the performance of technology, products and services and to identify the processes causing the most pollution or consuming the most energy or material during the life cycle, and also how they can apply the concepts of industrial symbiosis and synergy, cleaner production, 3Rs (recycling, reduce and reuse) and eco-efficiency strategies to attain economic and environmentally feasible solutions.

In Cluster 3, students are introduced to sustainable technologies, for example the concept of green chemistry and green engineering to improve the efficiency of chemical reactions to reduce waste. The students have also been shown how science in nature can be followed to design an efficient process or technology that conserves resources and reduces pollution. This cluster also discusses alternative and new technologies including information technology, nanotechnology and renewable energy.

All the tools, methods and strategies described help to conserve resources and combat pollution in an economically feasible way to preserve resources for future generations through sustainable engineering solutions.

How the unit has been conducted to help students apply the concept of industrial ecology in engineering design is described below. In the first two weeks, students are introduced to sustainability principles, the impact of technological development on natural resources degradation and indigenous cultures. In the next eight weeks, students are taught the tools and methods of industrial ecology. Each lecture has been designed so that the theoretical presentation is followed by a related case study to help students understand the significance 
of these topics. For example, following the lecture on biomimicry, a case study 'Learning from the dolphin' shows the students how the morphology of dolphin skin can be applied to design an efficient marine locomotive to reduce drag force, energy consumption and, therefore, overall environmental emissions. The case study, 'Is biodiesel a carbon neutral fuel?' was presented after the life cycle assessment to enable students to think critically about renewable fuels and to show that they are not completely greenhouse gas emission free from the life cycle point of view.

Assignments were developed so that students can apply theory to practice. The task consisted of life cycle assessment of chosen products, and then assessment of the economic and environmental benefits of the application of cleaner production and eco-efficiency strategies, and potential industrial symbiosis. The students perform this task in a group to enhance their interdisciplinary and multidisciplinary team skills. The example, the students from the chemical and mechanical engineering departments worked on the environmental performance of electricity generation from biodiesel, sharing their discipline-specific knowledge to carry out the task. The multidisciplinary approach means the students take into account economic, environmental and social aspects of industrial ecology to assess the sustainability of their group projects.

Furthermore, Curtin University has typically $60 \%$ of its students from overseas which creates an opportunity for local students to work in a multicultural team to develop sustainable engineering solutions.

\subsection{Postgraduate level}

CECP at Curtin University offers a Masters degree in Sustainability that includes units in industrial ecology, eco-efficiency, cleaner production tools and sustainable technology. Most of the enrolments in these units are from students from engineering backgrounds, 
predominantly from mining, refinery and manufacturing industries and engineering consulting firms.

Each postgraduate unit is divided into four teaching modules. The assessment of these units is based on assignments only, where the students are required to perform four tasks for four modules, and the tasks for consecutive modules are usually interlinked. The students can choose their own case studies for carrying out these tasks to apply theory to practice. In some cases, a confidentiality agreement has to be signed in order to encourage students to use their industry- or job-related data to apply theory to practice.

In most cases, new tasks are built upon the previous task which consolidate learning. For example, students in the Sustainable Energy unit had to carry out an energy audit of their chosen organisation or workplace as a part of their second assignment. Completion of the energy audit enabled the students to assess the energy saving potential of efficient technologies in the third assignment. In the last assignment, they assessed the environmental pollution mitigation potential of using the most cost-effective and efficient technological options available for energy production.

Students have been equipped with environmental management software to apply cleaner production strategies for attaining sustainable engineering solutions. In the Cleaner Production Tools unit, the students are shown how to use SimaPro life cycle assessment software in order to assess the environmental performance of a product. Using this software, the students can develop environmental pollution reduction strategies by identifying inputs, processes, and technologies or 'hotspots' causing the most environmental emissions during the life cycle of products. Once they have identified the hotspots using the software, they can determine economically viable cleaner production strategies in order to improve the environmental performance of the production process. 


\section{Student benefits from including industrial ecology in the engineering curriculum}

\subsection{Student satisfaction at undergraduate and postgraduate levels}

The information gathered from the unit evaluation reports since 2006 for both undergraduate and postgraduate courses have been analysed to assess student satisfaction in the sustainability engineering units.

Figure 2 shows student overall satisfaction, which is based on the quality of material contents, feedback on assignment tasks, learning outcomes, reading materials, delivery methods, motivation and work load for industrial ecology units taught at undergraduate and postgraduate levels for 2006-10. As evidenced from the evaluation reports, motivation and work-load issues have been found to be challenging to obtain a good overall satisfaction score at undergraduate level compared to postgraduate level. Undergraduate students may not be sufficiently mature to be motivated to understand the complexity of sustainability issues. Furthermore, students may be more interested in their potential grades than how they will apply sustainability principles in their future career. Some students who have been unable to demonstrate their ability to address sustainability issues in their assessment may consider that they were dissatisfied with this unit.

Similarly, Boyle (2004) found most of the students entering post-secondary education do not have an understanding of sustainability even at a basic level, having focused more on their personal needs satisfaction, and therefore have difficulty in determining how they fit into society and how society functions. Given the multidisciplinary dimensions of the course and the techno-centric ideas prevalent among students, it may be challenging to engage students with sustainability issues at an undergraduate level (El-Zein et al., 2008). Sustainability scientists call for education that produces professionals with a good 
understanding of sustainability issues, but students often have different ideas, often based on an expectation of continued unlimited economic growth (Ashford, 2004; Kelly, 2006).

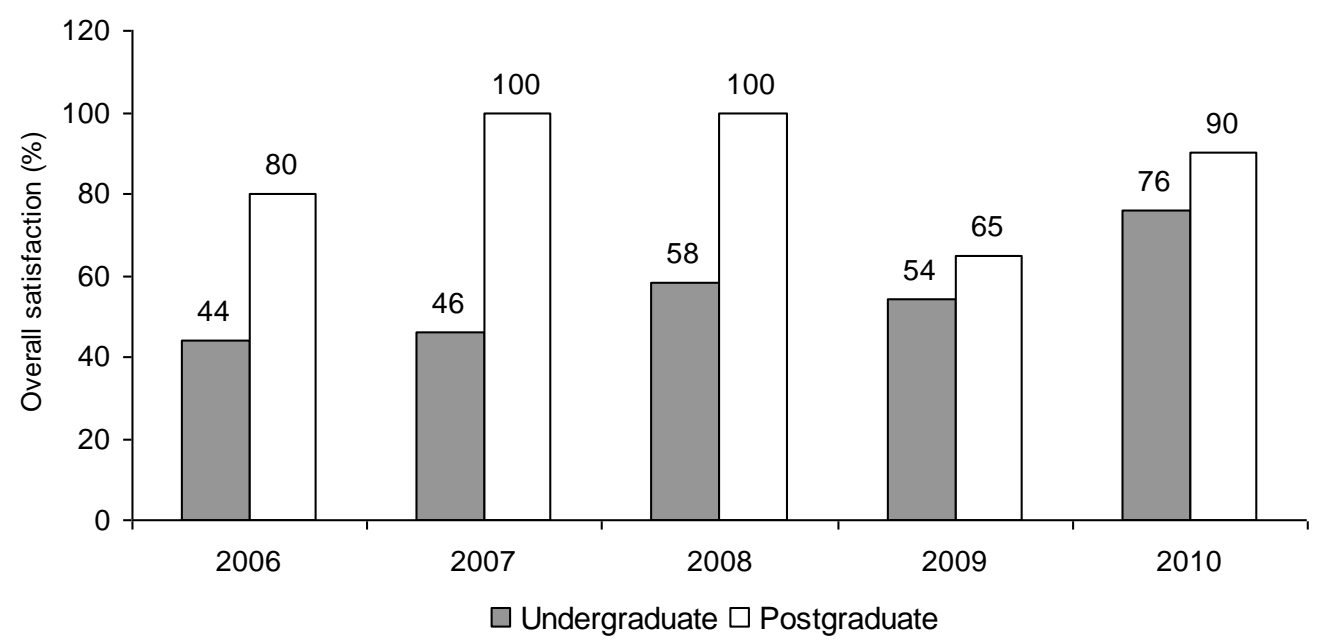

Figure 2. Student satisfaction in sustainable engineering units 2006-10

Students in postgraduate units are generally interested in developing their knowledge and tools to apply sustainability principles in their organisations, and are more mature because of their work experience and social interaction. Boyle (2004) also recognises that providing Masters programs in sustainability engineering to students who have completed an undergraduate degree in engineering and may have some experience as an engineer will enhance understanding of sustainability concepts. However, since there are few engineering students enrolled in sustainability Masters programs, the influence of these students on engineering for sustainable development is still small. 


\subsection{Improving student interest in sustainability engineering through pedagogical strategies}

In order to score better overall satisfaction by increasing motivation and optimising work load in the undergraduate sustainability engineering unit, passive (such as lecturing, writing exercises, problem demonstrations) and active (such as PBL, case studies) learning pedagogical strategies have been applied over the last five years to enhance students' satisfaction.

Initially, the overall satisfaction in the ESD unit in 2006 was $44 \%$ as students thought that the workload was excessive. In addition to completing four assignments, students undertook a closed book examination at the end of the semester. In the following year this unit was restructured by withdrawing the examination and including innovative assessment tasks that cover all theory discussed in the unit. In addition, students had to undertake their tasks in pairs, which taught them to work as a team, to apply theory to practice and to collect the information to carry out the assignment.

The first task was a triple bottom line analysis of a discipline-specific case study and the second task was developed on the basis of a PBL approach that consisted of three parts: life cycle assessment of the chosen product, economic and environmental benefits of cleaner production strategies and the development of an environmental management program to implement cleaner production strategies. To make the unit more interesting, guest lecturers were invited from the British Petroleum (BP) refinery, GHD Pty Ltd and Sinclair Knight Merz to present discipline-specific case studies on design for the environment, environmental management systems and engineering for sustainable development in order to provide students with real-world examples. This teaching method has also been supported by Mulder (2004), where invited lecturers convey the message on sustainable development by showing the connection between theory and practice. 
To increase the level of student attendance and to enhance communication, interesting documentaries, for example An Inconvenient Truth, Eleventh Hour and Protecting Your Profit were shown in order to enhance students' understanding about sustainability and cleaner production strategies. In addition, students were taught how to develop a promotional poster and how to use EcoStrat software to compare the environmental performance of existing and environmentally friendly products.

Despite applying these teaching methods, the overall satisfaction (46\%) did not improve much in 2007. This is mainly because the collection of data for carrying out the assignments was found to be too laborious for the students.

In order to reduce the pressure on data collection, some qualitative analyses were introduced to replace the quantitative analyses. For example, instead of determining quantitative values of environmental and economic benefits of industrial symbiosis, students were asked to draw a flowchart showing how the exchange of inputs and outputs takes place between industries. While this improved the overall satisfaction significantly in 2008, plagiarism in group assignments along with group disputes were frequent issues. An examination was again introduced in 2009 with $60 \%$ of the total marks allocated for the closed book examination and $40 \%$ for the assignments. The overall satisfaction dropped again in 2009, as students were not aware of the nature of the examination questions and experienced difficulties in understanding how theories and case studies presented during the lectures are related.

In order to overcome this problem, three open book quizzes during lectures were introduced in the following semester that covered all 12 lecture topics. This helped students understand how their knowledge about the subject would be tested and helped them prepare for the examination. As a result, the overall satisfaction increased to $76 \%$. 


\subsection{Implications of sustainability knowledge}

Some postgraduate students' comments after the completion of the course have been analysed to assess the implications of industrial ecology in the students' workplaces and future career.

It appears from these comments that the students have benefited in developing sustainable engineering solutions in their workplaces. They were able to relate to the need to consider social, economic and environmental parameters in their decision making and how to involve the community in the engineering design process. They needed to assess the economic and environmental implications of industrial ecology and to develop appropriate roles of direct and indirect stakeholders' engagement in attaining sustainable engineering solutions (Table 1). In addition, students have been provided with the flexibility to understand the concept of sustainability as it pertains to their professional careers and current jobs.

Many postgraduate students from engineering companies, who were working in the environmental area, have been able to apply sustainability engineering solutions after completion of the Masters in Sustainability course (Table 1). The concept of industrial ecology that deals with process technology rather than end of pipe solutions enabled students to design sustainable engineering solutions by creating cost, waste and resources saving opportunities. The tasks of this course were application driven, with students able to apply their knowledge to real business settings. In addition, this challenged their knowledge and thinking demanded for sustainable engineering solutions. 
Table 1. Students' statements about CECP sustainability programs

\begin{tabular}{ll}
\hline $\begin{array}{l}\text { Student names, Statements } \\
\text { organisations }\end{array}$ & Source
\end{tabular}

\begin{tabular}{ll}
\hline Bethany & Even though I work in the environmental field sometimes we \\
Challen, Mount & are just too involved in the day to day operations to look at \\
Newman Mines & what is going on in the wider community. Having this increased \\
& knowledge enables me to critically evaluate my own company's \\
& decisions and activities and also, where possible, to try to \\
& influence the direction we take. The course is particularly \\
& enjoyable as the assignments are challenging and require \\
& thorough understanding and analysis of the information \\
& presented.
\end{tabular}

Email February 2007

An international For an engineer, it paints a picture of the scarcity and student from importance of the remaining energy resources, and the impacts Africa that energy in general, has on sustainability from a social, economic and environmental perspective. It opened and challenged my thinking to what may be demanded of engineers in the near future, because they are major stakeholders in achieving sustainability.

Simon Winter, The postgraduate course in Cleaner Production provides the Alcoa Pinjarra tools we need to move from yesterday's end of pipe solutions Refinery towards a better future. It is an excellent course that is presented in a clear concise format and provides the students with the knowledge needed to develop cost, waste, and resource saving opportunities for their company.

Ross Hamilton, The Masters of Sustainability Management Program has been Quality and great in keeping me abreast of the latest research and concepts Environmental of sustainability. Better still, the practically oriented projects Manager, have enabled me to apply my studies to real business settings.

Teaching and Learning, Curtin University of Technology

Postgraduate program brochure, Cleaner Production, Curtin University

Postgraduate program brochure, Cleaner Production, Macmahon

Curtin University 


\section{Conclusion}

The future of engineering education in a rapidly changing world is dependent on the ability of that education to develop talented engineers, proficient in technical acumen, sustainability assessment, social awareness and communication skills. While in the past changes in education paradigms have occurred over long periods of time and were largely driven by science and technology, the modern environment for engineers is fraught with growth challenges, complex political and socio-political hurdles and economic goals that do not necessarily include triple bottom line objectives. In addition, the university environment can also temper the potential outcomes from increasing the sustainability content in engineering education given the general lack of student maturity in understanding the value of sustainability objectives in engineering together with course limitations on sustainability content and the arduous and lengthy processes involved in changing course curricula.

Curtin University has relied on the teaching of one major sustainability-related unit at undergraduate level together with the postgraduate units offered by CECP as a major part of the sustainability education on offer to its students.

This paper has highlighted the value of industrial ecology in developing sustainability concepts for engineering education and in providing a template for both assessment and understanding in terms of engineering responsibilities as they apply to modern sustainability principles. In addition, the paper explained how different pedagogical strategies, including passive and active learning, have been applied over five years to enhance student satisfaction. Some of these useful pedagogical approaches are the inclusion of case study presentation from industry and the use of documentary films and sustainability-related engineering problems. Interviewing recent engineering graduates who completed the undergraduate ESD 
unit regarding the application of their engineering sustainability knowledge in their professional career was beyond the scope of this research. However, some postgraduate students' comments after the completion of the course indicated that they have benefited in developing sustainable engineering solutions in their workplace.

The industrial ecology course helps to provide a framework for incorporating relevant and impactful strategies in making engineering more sustainable. It is an important link between reducing the environmental impacts associated with modern consumption in an economically feasible way in order to preserve resources for future generations through sustainable engineering solutions. Further research on how students' comprehension of sustainability has changed after the introduction of those modules can be carried out.

\section{Acknowledgement}

Michele Rosano for reviewing the conference version of the non-refereed paper and Joy van der Laan for providing editorial support.

\section{Notes}

1. $\mathrm{I}=\mathrm{PAT}$ where $\mathrm{I}$ is the impact (total impact of mankind on the planet), $\mathrm{P}$ is the population (total population size), A is affluence (number of products or services consumed per person) and $\mathrm{T}$ is technology (impact per unit consumed, often called technology efficiency). 


\section{References}

Ashford, N. A. (2004), "Major challenges to engineering education for sustainable development", International Journal of Sustainability in Higher Education, Vol. 5 No. 3, pp. 239-250.

Baird, C, and Cann, M (2006), "Environmental Chemistry, 3rd eEdition. Book \& Media Reviews", Journal of Chemical Education. Vol .83 No. 2, pp. 217-222.

Biswas, W K, John, M B, Batt, P, and Noonan, J (2010), "Environmental supply chain management in Australian grain industries - A life cycle assessment approach”, Handbook of Corporate Sustainability: Frameworks, Strategies and Tools, Quaddus M. A. and Siddique M. A. B. (EDs), Edward Elgar, USA.

Biswas, W. K. (2009) "Life cycle assessment of seawater desalination in Western Australia", World Academy of Science, Technology and Technology, Vol 35, pp. 399-405.

Biswas, W. K. , Barton, L. and Carter, D (2011), "Biodiesel production in a semi-arid environment - a life cycle assessment approach", Environmental Science and Technology, Vol. 45, pp. 3069-3074.

Biswas, W. K., Bryce, P. and Diesendorf M. (2001), "Model for Empowering Rural Poor through Renewable Energy in Bangladesh”, Environmental Science and Policy, Vol. 4 No. 6, pp. 333-344.

Boyle, C. (2004), "Considerations on educating engineers in sustainability", International Journal for Sustainability in Higher Education, Vol. 5 No. 2, pp. 147-155.

Bryce, P, Johnson, S and, Yasukawa, K (2004), “Implementing a program in sustainability for engineering at University of Technology, Sydney", International Journal of Sustainability in Higher Education, Vol. 5 No. 3, pp. 267-277. 
Chertow, M (2006), Preventing pollution through industrial symbiosis, 10th Canadian Pollution Prevention Roundtable Halifax, Nova Scotia June 14.

Desha, C, and Hargroves, K (2009), "Surveying the state of higher education in energy efficiency in Aaustralian engineering curriculum”, Journal of Cleaner Production, Vol. 18 No. 7, pp. 652-658.

Desha, C, Hargroves, K, and Smith, M (2009), "Addressing the time lag dilemma in curriculum renewal towards engineering education for sustainable development", International Journal of Sustainability in Higher Education, Vol. 10 No. 2, pp.184-199.

Diesendorf, M. (2000), "Sustainability and sustainable development", Dunphy, D., Benveniste, J., Griffiths, A and Sutton, P. (Eds), Sustainability: the Corporate Challenge of the 21st Century, Allen \& Unwin, Sydney.

Ehrenfeld, J and Chertow, M (2002), "Industrial symbiosis: the legacy of Kalundborg", Handbook of industrial ecology, Ayers R. and Ayers L. (eds), Edward Edgar Publishing, Glos, UK.

El-Zein, A, Bowden, P, and Clarkeburn, H (2008), "Sustainability and ethics as decisionmaking paradigms in engineering curricula", International Journal of Sustainability in Higher Education, Vol. 9 No. 2, pp. 170-182.

Howgrave-Graham, A, and van Berkel, R (2007) “Assessment of cleaner production uptake: method development and trial with small businesses in Western Australia", Journal of Cleaner Production, Vol. 15 No. 8-9, pp. 787-797.

Jacobsen, N.B. ( 2006), "Industrial symbiosis in Kalundborg, Denmark: a quantitative assessment of economic and environmental aspects", Journal of Industrial Ecology, Vol. 10, no. $1-2$, pp. $239-255$.

Kamp, L (2006), "Engineering education is sustainable development at Delft University of Technology", Journal of Cleaner Production, Vol. 14, pp. 928-931. 
Kelly, P. (2006), "Letter from the oasis: helping engineering students to become sustainable professionals", Futures, Vol. 38, pp. 696-707.

Loden, D., and Biswas, W.K. (2010), Enhancement of university curriculum and secondary school education through utilisation of sustainable engineering and appropriate technology workshops, peer reviewed paper, Proceedings of the 2010 AaeE (Australasian Association of Engineering Education) Conference, Sydney.

Mulder, K. (2004), "Engineering education in sustainable development : sustainability as a tool to open up the windows of engineering institutions", Business Strategies and the Environment, Vol. 13, pp. 275-285.

Müller, R, and Kuc, R (2006), "Biosonar-inspired technology: goals, challenges and insights", Bioinspiration \& Biomimetics, Vol. 2 No. 4, pp. 146-161.

Segalàs J., Ferrer-Balas, D., and Mulder, K.F. (2009), Introducing Sustainable Development in Engineering Education: Competences, Pedagogy and Curriculum, 37 ${ }^{\text {th }}$ European Society for Engineering Education (SEFI) Annual Conference, Rotterdam, Netherlands.

van Beers D. and Biswas W. K. (2008), “A Regional Synergy Approach to Energy Recovery: The Case of the Kwinana Industrial Area, Western Australia”, Journal of Energy Conservation and Management, Vol 49, pp. 3051-3062.

van Beers, D, Corder, G, Bossilkov, A and, van Berkel, R (2007), "Industrial Symbiosis in the Australian Minerals Industry: The Cases of Kwinana and Gladstone”, Journal of Industrial Ecology, Vol. 11 No. 1, pp. 55-72.

van Beers, D., Bossilkov A. and van Berkel R. (2008), “A regional synergy approach to advance sustainable water use: a case study using Kwinana (Western Australia)”, Australasian Journal of Environmental Management, Vol. 15, pp. 149-158.

van Berkel, R (2007), “Cleaner production and eco-efficiency initiatives in Western Australia 1996-2004”, Journal of Cleaner Production, Vol 15 No. 8-9, pp. 741-755. 


\section{About the author}

Wahidul Biswas is a Senior Lecturer and Programme Coordinator at the Centre of Excellence in Cleaner Production, Curtin University, Western Australia. Wahidul was trained as a Mechanical Engineer, researching the performance of diesel engines using biogas fuel. He has a Masters in Environmental Technology from Imperial College, London, and a PhD in Sustainable Futures from the University of Technology, Sydney. He teaches and coordinates postgraduate units on Cleaner Production Tools, Eco-Efficiency, Global Sustainability Studies, Environmental Studies, and Sustainable Energy and a core undergraduate Engineering unit, Engineering for Sustainable Development. Wahidul has carried out extensive life cycle assessment research on greenhouse gas emissions from the Australian agricultural, alternative fuels, building and construction, manufacturing, mining, gas and water sectors. 